\title{
Investigação da qualidade de farinhas enriquecidas utilizando Análise por Componentes Principais (PCA)
}

\author{
Enriched flour quality investigation using Principal Component Analysis (PCA)
}

\author{
Bruno Thiago SOEIRO ${ }^{1}$, Thaís Rezende BOEN ${ }^{1}$, \\ Edenir Rodrigues PEREIRA-FILHO², Juliana Azevedo LIMA-PALLONE ${ }^{1 *}$
}

\section{Resumo}

Alguns países, incluindo o Brasil (RDC 344, 2002), instituíram uma regulamentação indicando que farinhas de milho e trigo devem ser enriquecidas com ácido fólico e ferro. O principal objetivo deste trabalho foi a avaliação de algumas características de farinhas enriquecidas usando a Análise por Componentes Principais (PCA). Parâmetros como o teor de ácido fólico, ferro, proteína, lipídios, umidade, cinzas e carboidratos foram avaliados em 30 embalagens de farinhas adquiridas em comércio local. As farinhas de trigo e milho apresentaram, em média, composição centesimal aceitável de acordo com a Legislação Brasileira. Para as farinhas de trigo, a concentração de ácido fólico estava, em média, próxima ao esperado. As farinhas de milho continham quantidade superior da vitamina. Para os dois tipos de farinha, constatou-se teor de ferro acima do valor declarado no rótulo dos produtos. Uma matriz com 30 linhas (amostras) e 7 colunas (variáveis) foi organizada e os dados foram autoescalados. A primeira informação observada foi uma clara diferenciação entre os tipos de farinhas. As farinhas de trigo foram caracterizadas por maior quantidade de proteínas, umidade e cinzas. Por outro lado, as farinhas de milho apresentaram maior concentração de ferro, lipídios, carboidratos e ácido fólico. Foi possível notar também que farinhas acondicionadas em embalagens de plástico apresentaram menor quantidade de ácido fólico $\left(152 \mu \mathrm{g} .100 \mathrm{~g}^{-1}\right.$, em média), quando comparadas às amostras armazenadas em embalagens de papel ( $259 \mu \mathrm{g} .100 \mathrm{~g}^{-1}$, em média). Esse estudo pode fornecer ferramentas importantes para a avaliação dos programas de enriquecimento de alimentos com ácido fólico, principalmente, por apontar, preliminarmente, para a importância do tipo de embalagem para o acondicionamento das farinhas enriquecidas com a vitamina.

Palavras-chave: farinhas enriquecidas; ferro; ácido fólico; quimiometria.

\begin{abstract}
Some countries, including Brazil (resolution - RDC \# 344, 2004), have issued a regulation stipulating that corn and wheat flours have to be fortified with folic acid and iron. The main objective of this work was to investigate some enriched flour characteristics using Principal Component Analysis (PCA). Wheat and corn flours presented, on average, acceptable centesimal composition according to the Brazilian Legislation. For the wheat flours investigated, the folic acid concentration was, on average, close to the expected value. Corn flours contained higher amount of vitamin. For both types of flour, the iron content exceeded the label claim of the products. Parameters, such as folic acid, iron, protein, lipids, moisture, ash, and carbohydrates content were present in 30 flour packages purchased from the local market. A matrix with 30 rows and 7 columns was organized and the data was autoscaled. The first information observed was an expected discrimination according to the type of flour. The wheat flours were characterized by high protein, moisture, and ash content. On the other hand, the corn flours had high iron, carbohydrates, lipids, and folic acid. Another important observation was related to the package type. It was noted that the flours packed in plastic bags had less folic acid $\left(152 \mu \mathrm{g} .100 \mathrm{~g}^{-1}\right.$, on average $)$ than those packed in paper $\left(259 \mu \mathrm{g} .100 \mathrm{~g}^{-1}\right.$, on average $)$ bags. This behavior is probably due to the light incidence during the storage period. This study can be useful to help the governmental authorities in the enriched food program evaluation. In this case, it will be possible to set suitable rules for appropriate food packaging.

Keywords: enriched flour; iron; folic acid; chemometry.
\end{abstract}

\section{Introdução}

A qualidade de farinhas é determinada por uma variedade de características que podem ser classificadas em físicas, químicas, enzimáticas e funcionais (RASPER, 1991). Dentre as características físicas e químicas, o estabelecimento da composição centesimal está diretamente relacionado à classificação desses produtos em relação aos padrões de qualidade e identidade (AGÊNCIA..., 2008). Para o caso especial de farinhas enriquecidas com vitaminas e minerais, os componentes majoritários podem influenciar diretamente na manutenção dos micronutrientes, principalmente durante a estocagem desses produtos (GUTKOSKI; JACOBSEN, 2002).

A fortificação de alimentos com nutrientes é uma prática aceita e empregada pelos processadores de alimentos desde a

Recebido para publicação em 17/7/2008

Aceito para publicação em 8/7/2009 (003441)

${ }^{1}$ Centro de Ciências Exatas, Ambientais e de Tecnologias, Faculdade de Química, Pontifícia Universidade Católica - PUC-Campinas, Rod. D. Pedro I, Km 136, CEP 13086-900, Campinas - SP, Brasil, E-mail: juliana.pallone@gmail.com

${ }^{2}$ Departamento de Química, Centro de Ciências Exatas e de Tecnologia, Universidade Federal de São Carlos - UFSCar, Rod. Washington Luís (SP-310), Km 235, CEP 13565-905, São Carlos - SP, Brasil

${ }^{*}$ A quem a correspondência deve ser enviada 
metade do século XX (REILLY, 1996) e tem como objetivo reforçar o valor nutritivo e prevenir ou corrigir deficiências de um ou vários nutrientes (AGÊNCIA..., 2008). No Brasil, a Resolução RDC 344, de 13 de dezembro de 2002, instituiu que, desde junho de 2004, as farinhas de trigo e milho deveriam ser enriquecidas com ácido fólico (150 $\mu \mathrm{g} .100 \mathrm{~g}^{-1}$ de farinha) e ferro (4,2 mg. $100 \mathrm{~g}^{-1}$ de farinha), sendo que tal obrigatoriedade tem como objetivo a prevenção de defeitos no fechamento do tubo neural e de anemia ferropriva (AGÊNCIA..., 2008).

Os Defeitos no Fechamento do Tubo Neural (DFTN) são malformações congênitas frequentes que ocorrem devido a uma falha no fechamento adequado do tubo neural embrionário (AGUIAR et al., 2003). Essas malformações estão entre as mais significativas causas congênitas de mortalidade infantil e representam o maior grupo de anomalias do sistema nervoso central, ocorrendo em cerca de um quarto de 1 milhão de nascimentos/ano em todo mundo (MOLLOY, 2005). Ocorrem entre o $26^{\circ}$ e $28^{\circ}$ dias de gestação, quando é formado o tubo neural (NEUHOUSER; BERESFORD, 2001). Dentre os DFTN podem ser citados a anencefalia, a espinha bífida e a encefalocele (GRILLO; SILVA, 2003). A carência de ácido fólico está diretamente associada ao surgimento dessa patologia (CZEIZEL; DUDAS, 1992; MOLLOY, 2005).

Por sua elevada e, às vezes, crescente prevalência em alguns países e regiões, as anemias configuram, na atualidade, o problema carencial de maior magnitude no mundo. De acordo com a World Health Report 2002 ("Reduzindo riscos, promovendo vida saudável") as deficiências nutricionais de ferro foram identificadas como o primeiro dentre os 10 principais fatores de risco para doenças e morte, com um impacto maior do que as deficiências de zinco e vitamina A (WORLD..., 2002). Estima-se que 2 bilhões de pessoas são afetadas em todo mundo (UNITED..., 2000). O risco de deficiências é maior quando os requerimentos de ferro são maiores como na primeira infância, adolescência e durante a gestação (LYNCH, 2005). Ingestão inadequada e consumo de alimentos com baixa biodisponibilidade de ferro são identificados como as principais causas de deficiências (RAO; PRABHAVATHI, 1978).

A Resolução RDC 344 (AGÊNCIA..., 2002) indica que as empresas devem assegurar que os compostos de ferro adicionados às farinhas sejam de grau alimentício e biodisponíveis e as formas sugeridas para a fortificação são: sulfato ferroso desidratado (seco), fumarato ferroso, ferro reduzido - 325 mesh Tyler, ferro eletrolítico - 325 mesh Tyler, EDTA de ferro e sódio (NaFeEDTA) e ferro bisglina quelado.

A determinação do teor de ácido fólico, ferro e composição centesimal nas farinhas enriquecidas pode fornecer ferramenta para a avaliação da concentração disponível a ser ingerida, correlacionar os valores à biodisponibilidade dos nutrientes e, posteriormente, fornecer informações para os estudos epidemiológicos que deverão avaliar o impacto da obrigatoriedade do enriquecimento de farinhas.
A Quimiometria é uma área especificamente destinada à análise de dados químicos de natureza multivariada (FERREIRA et al., 1999). Os métodos multivariados consideram a correlação entre muitas variáveis analisadas simultaneamente, permitindo a extração de uma quantidade maior de informações, muitas vezes impossível quando se analisa variável a variável (FERREIRA et al., 1999).

A base fundamental para a maioria dos métodos modernos para tratamento de dados multivariados é o PCA - Análise por Componentes Principais (em inglês "Principal Component Analysis"), que tem por finalidade básica a redução de dados a partir de combinações lineares das variáveis originais (BEEBE; PELL; SEASHOLTZ, 1998). Para tanto, constrói-se um novo sistema de eixos para representar as amostras, no qual a natureza multivariada dos dados pode ser visualizada em poucas dimensões (FERREIRA et al., 1999). Isso é feito através do cálculo de componentes principais obtidos efetuando-se combinações lineares de variáveis originais. PCA é um método exploratório, porque auxilia na elaboração de hipóteses gerais a partir dos dados coletados, contrastando com estudos direcionados nos quais hipóteses prévias são testadas. É também capaz de separar a informação importante da redundante e aleatória (BEEBE; PELL; SEASHOLTZ, 1998).

O objetivo deste trabalho foi estabelecer o teor de ácido fólico, ferro, umidade, cinzas, proteínas, lipídios e carboidratos em amostras de farinhas de trigo e milho enriquecidas e a aplicação de PCA para o tratamento dos dados.

\section{Material e métodos}

Foram empregadas 3 diferentes marcas de Farinhas de Trigo tipo especial (FT) e de Milho flocada (FM) enriquecidas com ferro e ácido fólico, disponíveis comercialmente na cidade de Campinas, São Paulo, Brasil. Foram avaliadas 3 marcas (A, B, C), em 5 lotes $(1,2,3,4,5)$. As farinhas de trigo foram inicialmente homogeneizadas e, posteriormente, amostradas em quarteador ( 3 bandejas, Metalúrgica Leonardo), com a obtenção de aproximadamente $100 \mathrm{~g}$ de amostra para as análises. Para as farinhas de milho flocadas, foi necessário efetuar-se a moagem (Moinho Ika, modelo A11), em laboratório e peneiramento (28 mesh, Bertel), antes da retirada de amostras para as análises. Seguiramse as determinações de ferro, umidade, cinzas, proteínas, lipídios e carboidratos em amostras de Farinhas de Trigo (FT) e Milho (FM).

Para a melhor avaliação dos dados obtidos, uma matriz com 30 linhas (amostras) e 7 colunas (variáveis) foi organizada e os dados foram autoescalados. Com o objetivo de se obter o máximo de informação sobre os dados, uma PCA foi calculada.

\subsection{Determinação do ácido fólico}

Foi utilizado como base o método validado por Boen et al. (2008) para a avaliação do ácido fólico em farinhas enriquecidas. Pesou-se, aproximadamente, 1,0 g da amostra. Seguiu-se a 
extração do ácido fólico utilizando-se $4,0 \mathrm{~mL}$ de hidróxido de potássio e 3,0 mL de acetonitrila. Deixou-se em ultrassom por 10 minutos. Adicionaram-se 2,0 $\mathrm{mL}$ de tampão fosfato e $0,5 \mathrm{~mL}$ de ácido tricloroacético e completou-se o volume com tampão fosfato, em balão volumétrico de $10 \mathrm{~mL}$. Filtrou-se em papel de filtro qualitativo. Efetuou-se, posteriormente, a filtração em membrana Millipore (FHLP 01300). Para a análise cromatográfica, $50 \mu \mathrm{L}$ do extrato foram injetados. Utilizou-se coluna de $\mathrm{C}_{18}$ e fase móvel composta por solução de ácido acético em água, a pH 2,8 e acetonitrila, em sistema gradiente de eluição. $\mathrm{O}$ processo de separação teve início com $100 \%$ da fase móvel aquosa acidificada, chegando em 23 minutos a $24 \%$ de acetonitrila e $76 \%$ da fase aquosa acidificada. A detecção foi feita espectrofotometricamente a $290 \mathrm{~nm}$ (região do Ultravioleta), em Detector de Arranjo de Diodos (DAD). A identificação do pico do ácido fólico foi realizada através da comparação dos tempos de retenção obtidos para padrão e amostra, cocromatografia e espectro de absorção obtido no DAD. A quantificação foi feita por padronização externa. As determinações foram feitas em triplicatas.

\subsection{Determinação do ferro}

Utilizando-se papéis vegetais, pesou-se cerca de $0,6000 \mathrm{~g}$ de farinhas de trigo e milho. As amostras foram transferidas para tubos de digestão e foram adicionados aos tubos $4 \mathrm{~mL}$ de ácido nítrico concentrado. Prepararam-se, também, dois tubos "brancos" (sem as amostras). Posicionaram-se pequenos funis na entrada de cada tubo de digestão, e estes foram levados para o bloco digestor e iniciou-se o aquecimento. Ajustouse a temperatura para $100{ }^{\circ} \mathrm{C}$. Os funis permitiram que o ácido nítrico ficasse em refluxo. Manteve-se o aquecimento por 2 horas. Retiraram-se os tubos do aquecimento e, após o resfriamento, adicionou-se $1 \mathrm{~mL}$ de peróxido de hidrogênio em cada tubo (inclusive nos brancos). Os tubos foram levados novamente para o bloco e, desta vez, ajustou-se a temperatura para $110^{\circ} \mathrm{C}$, por 30 minutos. Aumentou-se a temperatura para $130{ }^{\circ} \mathrm{C}$ e deixou-se por 1 hora. Retiraram-se os tubos do bloco e aguardou-se o resfriamento. Adicionou-se uma pequena quantidade de água $(5 \mathrm{~mL})$ aos tubos de digestão. Os tubos foram posicionados em um banho de ultrassom por alguns segundos. Transferiu-se o conteúdo dos tubos para balões volumétricos de $25 \mathrm{~mL}$ e completou-se o volume. Efetuaramse as determinações de ferro, em triplicatas, utilizando-se a técnica de Espectrometria de Absorção Atômica com Chama (ANALYTICAL..., 1987).

\subsection{Análise da composição centesimal (ASSOCIATION..., 2006)}

\section{Umidade}

O método utilizado foi o de secagem em estufa com circulação de $\operatorname{ar}\left(105^{\circ} \mathrm{C}\right)$ por aproximadamente 4 horas. Todas as determinações foram feitas em triplicatas.

\section{Cinzas}

O método empregado foi o da incineração em mufla por 4 horas, a $550{ }^{\circ} \mathrm{C}$. Todas as determinações foram feitas em triplicatas.

\section{Proteínas}

A determinação de proteínas foi realizada pelo método de Kjeldahl. Utilizou-se o fator de conversão de 5,70, para farinhas de trigo e 6,25, para farinhas de milho. Todas as determinações foram feitas em triplicatas.

\section{Lipídios}

O método utilizado foi o descrito por Bligh e Dyer (1959). O solvente foi eliminado por evaporação em estufa a $60^{\circ} \mathrm{C}$. Todas as determinações foram feitas em triplicata.

\section{Carboidratos}

O conteúdo de carboidratos foi determinado por diferença. Foi calculada a média da porcentagem de água, proteínas, lipídios e cinzas e o restante foi considerado carboidrato. Todas as determinações foram feitas em triplicata.

\subsection{Análise estatística}

Para a análise estatística foi utilizado o programa Origin 6.1 e a Análise por Componentes Principais foi feita com a utilização do software Pirouette.

\section{Resultados e discussão}

Na Tabela 1, podem ser observados os resultados obtidos para a determinação da composição centesimal, para 3 marcas (A, B e C) de Farinhas de Trigo (FT) e Milho (FM), em 5 diferentes lotes $(1,2,3,4$ e 5$)$ e os valores declarados nos rótulos de cada produto. De maneira geral, verificou-se que houve uma pequena variação para o teor de proteínas, lipídios, umidade, cinzas e, consequentemente, carboidratos, entre os lotes de farinhas avaliados.

Para as farinhas de trigo, os diferentes lotes da marca FT A, apresentaram níveis de proteínas e carboidratos próximos aos informados no rótulo. O teor de lipídios impresso na embalagem (0\%) está em desacordo com o valor obtido, para os 5 diferentes lotes (em média 1,3\%, em base seca). Para a porcentagem de cinzas, foram encontrados valores abaixo do declarado pelo fabricante. Para as FT B, os valores apresentados na embalagem, para lipídios, umidade e carboidratos mostraram-se bem próximos daqueles obtidos após análises. Entretanto, o teor de proteínas impresso no rótulo estava abaixo e o teor de cinzas encontrava-se acima daqueles obtidos em laboratório. Para FT C, observou-se o mesmo comportamento encontrado para FT B. Após a análise de variância, constatou-se haver diferença significativa entre o conteúdo médio de lipídios, umidade e carboidratos e não houve diferença significativa entre os valores obtidos para proteínas e cinzas, entre as diferentes marcas, com $95 \%$ de probabilidade. Apesar dessas diferenças, todas as amostras de farinhas de trigo avaliadas no trabalho seguiram, em média, as normas (teor de cinzas de $0,67 \% \pm 0,02$, proteínas $11,9 \% \pm 0,02$, em base seca), divulgadas pela Portaria de $n^{\circ} 354$ de 1996 (AGÊNCIA..., 1996), que caracterizam a farinha de trigo classificada como especial para uso doméstico: com teor de cinzas de $0,65 \%$, porcentagem de proteínas superior a $7 \%$ (base seca), não devendo a umidade exceder 15\%. 
Tabela 1. Composição centesimal obtida experimentalmente e valores declarados nos rótulos de farinhas de trigo e milho.

\begin{tabular}{|c|c|c|c|c|}
\hline \multirow[t]{2}{*}{ Farinhas/Marca/Lote } & \multicolumn{3}{|c|}{ Composição centesimal obtida experimentalmente } & \multirow{2}{*}{$\begin{array}{c}\text { Composição centesimal declarada no rótulo } \\
\text { das farinhas de trigo e milho }\end{array}$} \\
\hline & Análise & Faixa & $\% \mathrm{CV}$ & \\
\hline \multirow[t]{5}{*}{ FT A (1-5) } & Proteínas & $10,3-10,9$ & 2,4 & 10 \\
\hline & Lipídios & $1,2-1,3$ & 4,2 & 0 \\
\hline & Umidade & $11,1-12,6$ & 5,3 & 13 \\
\hline & Cinzas & $0,4-0,7$ & 15,0 & 0,8 \\
\hline & Carboidratos & $75,3-76,3$ & 0,6 & 76 \\
\hline \multirow[t]{5}{*}{ FT B (1-5) } & Proteínas & $9,9-10,4$ & 1,7 & 9,8 \\
\hline & Lipídios & $1,2-1,5$ & 0,5 & 1,4 \\
\hline & Umidade & $12,6-13,2$ & 2,0 & 13 \\
\hline & Cinzas & $0,5-0,6$ & 2,5 & 0,8 \\
\hline & Carboidratos & $74,4-75,4$ & 0,5 & 75,2 \\
\hline \multirow[t]{5}{*}{ FT C (1-5) } & Proteínas & $10,1-11,4$ & 4,5 & 9,8 \\
\hline & Lipídios & $1,2-1,6$ & 11,5 & 1,4 \\
\hline & Umidade & $11,8-12,7$ & 3,0 & 13 \\
\hline & Cinzas & $0,5-0,6$ & 8,9 & 0,8 \\
\hline & Carboidratos & $73,9-75,9$ & 1,0 & 75,2 \\
\hline \multirow[t]{5}{*}{ FM A (1-5) } & Proteínas & $6,3-6,9$ & 3,2 & 7,4 \\
\hline & Lipídios & $0,7-1,1$ & 15,9 & 0 \\
\hline & Umidade & $9,7-11,6$ & 6,8 & 11 \\
\hline & Cinzas & $0,3-0,4$ & 12,1 & 0,6 \\
\hline & Carboidratos & $80,7-82,7$ & 1,0 & 82 \\
\hline \multirow[t]{5}{*}{ FM B (1-5) } & Proteínas & $6,6-6,8$ & 1,1 & 8 \\
\hline & Lipídios & $2,5-3,2$ & 11,0 & 2 \\
\hline & Umidade & $11,7-12,0$ & 1,1 & 1 \\
\hline & Cinzas & $0,5-0,8$ & 19,0 & 0,6 \\
\hline & Carboidratos & $77,5-78,7$ & 0,6 & 72 \\
\hline \multirow[t]{5}{*}{ FM C (1-5) } & Proteínas & $6,2-7,0$ & 5,6 & 8 \\
\hline & Lipídios & $1,4-2,0$ & 12,1 & 2 \\
\hline & Umidade & $11,7-12,2$ & 2,0 & 11 \\
\hline & Cinzas & $0,4-0,5$ & 5,2 & 0,6 \\
\hline & Carboidratos & $78,6-82,2$ & 1,7 & 72 \\
\hline
\end{tabular}

\%CV - coeficiente de variação entre diferentes lotes; FT - Farinha de Trigo; A, B, C - marca; e FM- Farinha de Milho; A, B, C - marca.

Para as farinhas de milho, observou-se que, para FM A, os valores de umidade e carboidratos apresentaram-se conforme os informados pelo fabricante, entretanto, o teor de proteínas e cinzas estava abaixo e os valores para lipídios encontravam-se acima, quando comparados aos do rótulo (7,4, 0,6 e $0 \%$ para proteínas, cinzas e lipídios, respectivamente). Para FM B, o conteúdo de proteínas mostrou-se abaixo e o teor de carboidratos apresentou-se acima daqueles valores observados na embalagem. Para os demais componentes, foram encontradas porcentagens muito próximas, em média, aos valores informados pelo fabricante. Para FM C, apenas o teor de cinzas médio obtido diferiu do valor da embalagem, mostrandose abaixo da porcentagem declarada no rótulo. Apesar das diferenças encontradas entre marcas e lotes, a média dos valores obtidos para a composição centesimal nas amostras estava de acordo com a Resolução n 12 , de 1978 (AGÊNCIA..., 1978), que permite até $1 \%$ de cinzas, em farinhas de milho, em base seca. Os valores estabelecidos para umidade e proteínas (11,6 e 6,6\%) como parâmetros de qualidade de farinhas de milho são 14 e 6\% (em base seca). Portanto, os produtos avaliados apresentaram-se, de maneira geral, de acordo com as especificações. Após análise de variância, verificou-se haver diferença significativa entre o teor de lipídios, umidade, cinzas e carboidratos. Para proteínas, os valores não diferiram de forma significativa entre as marcas, com $95 \%$ de probabilidade.

As diferenças observadas na composição centesimal entre lotes e marcas de farinhas de milho e trigo se devem, provavelmente, a variações nos tipos de solo e nas condições de clima durante o cultivo e variedade do grão, além de parâmetros envolvidos na moagem e estocagem da matéria-prima, até a obtenção de cada um dos tipos de farinha. Além disso, as condições de armazenamento durante a fase de comercialização dos produtos também pode contribuir para alterações na porcentagem de umidade.

Os perfis cromatográficos, referentes à determinação de ácido fólico em amostras de farinha de trigo e farinha de milho flocada, bem como o cromatograma obtido após a injeção de padrão, estão apresentados na Figura 1. Neles, o pico do ácido fólico aparece isolado com tempo de retenção de aproximadamente 13,0 minutos. A pureza do pico foi verificada através dos parâmetros fornecidos pelo software HP-Chemstation, que confirmou a eficiência do sistema de separação cromatográfica. $\mathrm{O}$ teor da vitamina variou de 75 a 
$223 \mu \mathrm{g} .100 \mathrm{~g}^{-1}$ (em média $158 \mu \mathrm{g} .100 \mathrm{~g}^{-1}$ ) para as farinhas de trigo e de 258 a $488 \mu \mathrm{g} .100 \mathrm{~g}^{-1}$ (em média $324 \mu \mathrm{g} .100 \mathrm{~g}^{-1}$ ) para as farinhas de milho, conforme valores dispostos na Tabela 2 . Esses dados indicam que, especialmente para as farinhas de trigo, a concentração da vitamina mostrou-se, em média, próxima ao valor estipulado (150 $\left.\mu \mathrm{g} .100 \mathrm{~g}^{-1} \pm 20 \%\right)$. Para as farinhas de milho, o conteúdo de ácido fólico estava acima do valor estabelecido pela Legislação Brasileira (superior ao dobro) para todas as amostras. Entre as farinhas de trigo avaliadas, constatou-se diferença significativa tanto entre marcas quanto entre lotes, com um nível de confiança de 95\%. Para as farinhas de milho não se observou diferença significativa entre as marcas, entretanto, entre lotes da mesma marca, constatou-se diferença significativa, com o mesmo nível de confiança.
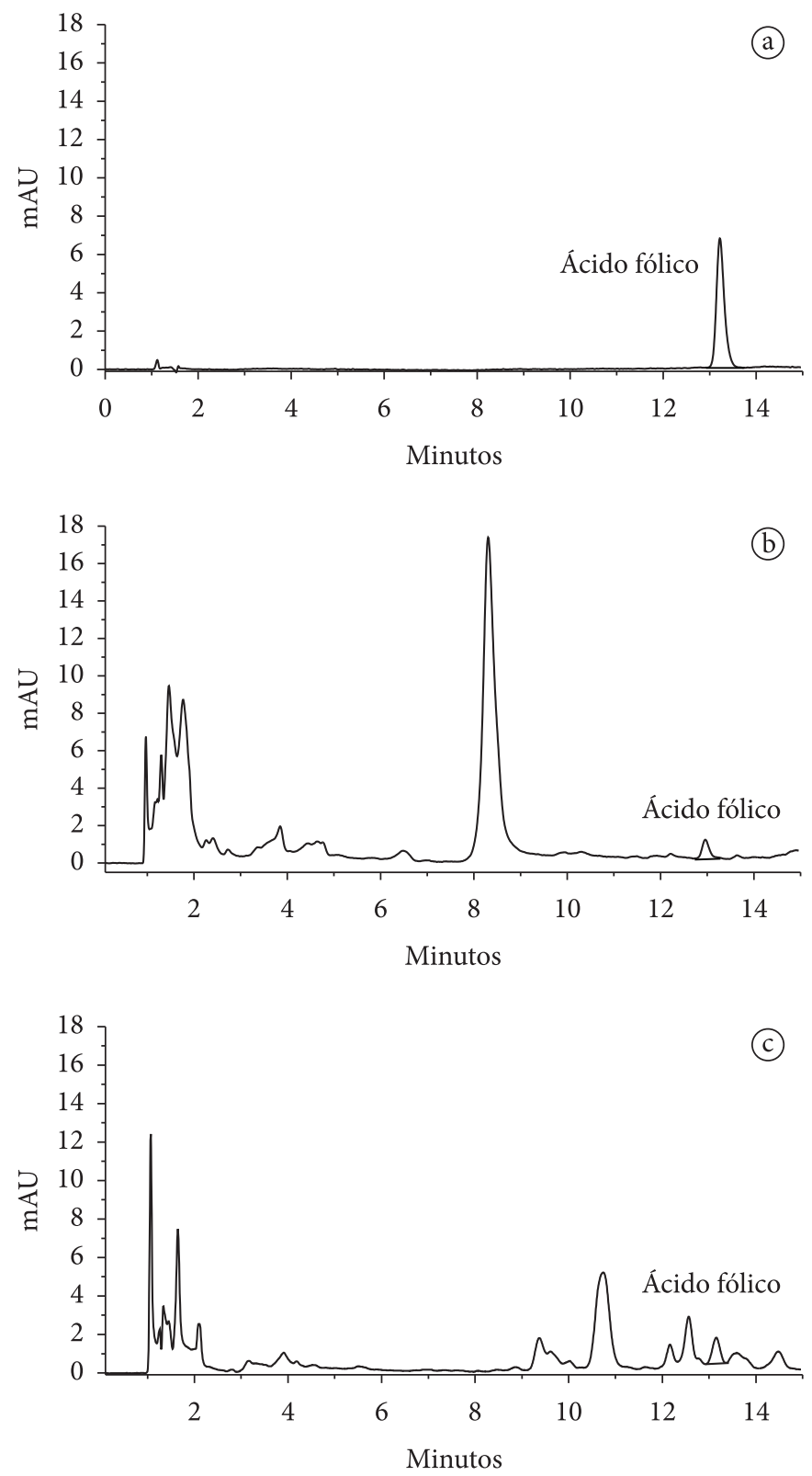

Figura 1. Perfis cromatográficos obtidos após a determinação do a) ácido fólico em padrão; b) farinha de trigo e c) farinha de milho.
Quanto às determinações de ferro, os resultados obtidos para as farinhas de trigo e milho, encontram-se na Tabela 3. De acordo com a Tabela de Composição de Alimentos (UNIVERSIDADE..., 2006), o teor de ferro naturalmente presente em farinhas é de 1,0 e $0,9 \mathrm{mg}^{100} \mathrm{~g}^{-1}$ para trigo e milho, respectivamente. Observa-se, então, que a concentração de ferro adicionado variou de 5,1 a 9,4 mg.100 g-1 (em média $\left.7,4 \mathrm{mg} .100 \mathrm{~g} \mathrm{~g}^{-1}\right)$ nas farinhas de trigo e de 6,4 a $10,9 \mathrm{mg} .100 \mathrm{~g}^{-1}$ (em média 8,5 mg.100 $\mathrm{g}^{-1}$ ) nas amostras de farinhas de milho avaliadas. Encontrou-se teor do mineral acima dos valores indicados na Resolução 344 (4,2 mg. $\left.100 \mathrm{~g}^{-1} \pm 20 \%\right)$ e declarados pelos fabricantes para a maioria das amostras. Vale ressaltar que o excesso no consumo de ferro pode trazer consequências negativas à saúde. Entre as marcas de farinhas de milho, verificou-se diferença significativa para as concentrações de ferro obtidas, já para as farinhas de trigo os valores não puderam ser considerados significativamente diferentes, com um nível de confiança de $95 \%$.

Para a PCA foram necessários 4 Componentes Principais para explicar $96 \%$ da variância total. Gráficos de Scores (A) e loadings (B) foram plotados por PC1 (57\%) versus PC2 (23\%), conforme Figura 2.

A primeira informação observada foi uma clara diferenciação entre as farinhas. As farinhas de trigo (círculos) foram caracterizadas por maior quantidade de proteínas, umidade e cinzas. Por outro lado, as farinhas de milho (quadrados) apresentaram maior concentração de ferro, lipídios, carboidratos e ácido fólico. Dessa forma, as farinhas que apresentaram maior teor de umidade, também continham menor teor de ácido fólico. A maior porcentagem de umidade pode atuar promovendo reações de degradação e oxidação. Apesar das farinhas de

Tabela 2. Teor de ácido fólico $\left(\mu \mathrm{g} .100 \mathrm{~g}^{-1}\right)$ em farinhas de trigo (FT) e milho (FM) enriquecidas e os valores médios.

\begin{tabular}{crr}
\hline Farinhas & \multicolumn{2}{c}{ Teor de ácido fólico } \\
\cline { 1 - 3 } Marcas/Lotes & \multicolumn{1}{c}{ Faixa } & Média \pm DP \\
\hline FT A (1-5) & $75-206$ & $152 \pm 54$ \\
FT B (1-5) & $174-223$ & $195 \pm 20$ \\
FT C (1-5) & $97-152$ & $127 \pm 24$ \\
FM A (1-5) & $258-307$ & $294 \pm 32$ \\
FM B (1-5) & $289-488$ & $349 \pm 80$ \\
FM C (1-5) & $285-398$ & $328 \pm 42$ \\
\hline
\end{tabular}

FT - farinha de trigo; FM- farinha de milho; e DP - desvio padrão relativo.

Tabela 3. Teor de ferro (mg.100 $\mathrm{g}^{-1}$ ) em farinhas de trigo (FT) e milho (FM) enriquecidas e valores médios.

\begin{tabular}{ccr}
\hline Farinhas & \multicolumn{2}{c}{ Teor de ferro } \\
\cline { 1 - 3 } \cline { 3 - 3 } Marcas/Lotes & Faixa & Média \pm DP \\
\hline FT A (1-5) & $5,1-7,7$ & $6,5 \pm 1,2$ \\
FT B (1-5) & $7,8-8,8$ & $8,3 \pm 0,4$ \\
FT C (1-5) & $5,4-9,4$ & $7,3 \pm 1,5$ \\
FM A (1-5) & $8,7-10,9$ & $9,8 \pm 1,1$ \\
FM B (1-5) & $6,4-8,1$ & $7,3 \pm 0,7$ \\
FM C (1-5) & $7,5-9,8$ & $8,4 \pm 1,0$ \\
\hline
\end{tabular}

FT-farinha de trigo; FM- farinha de milho; e DP-desvio padrão relativo. 

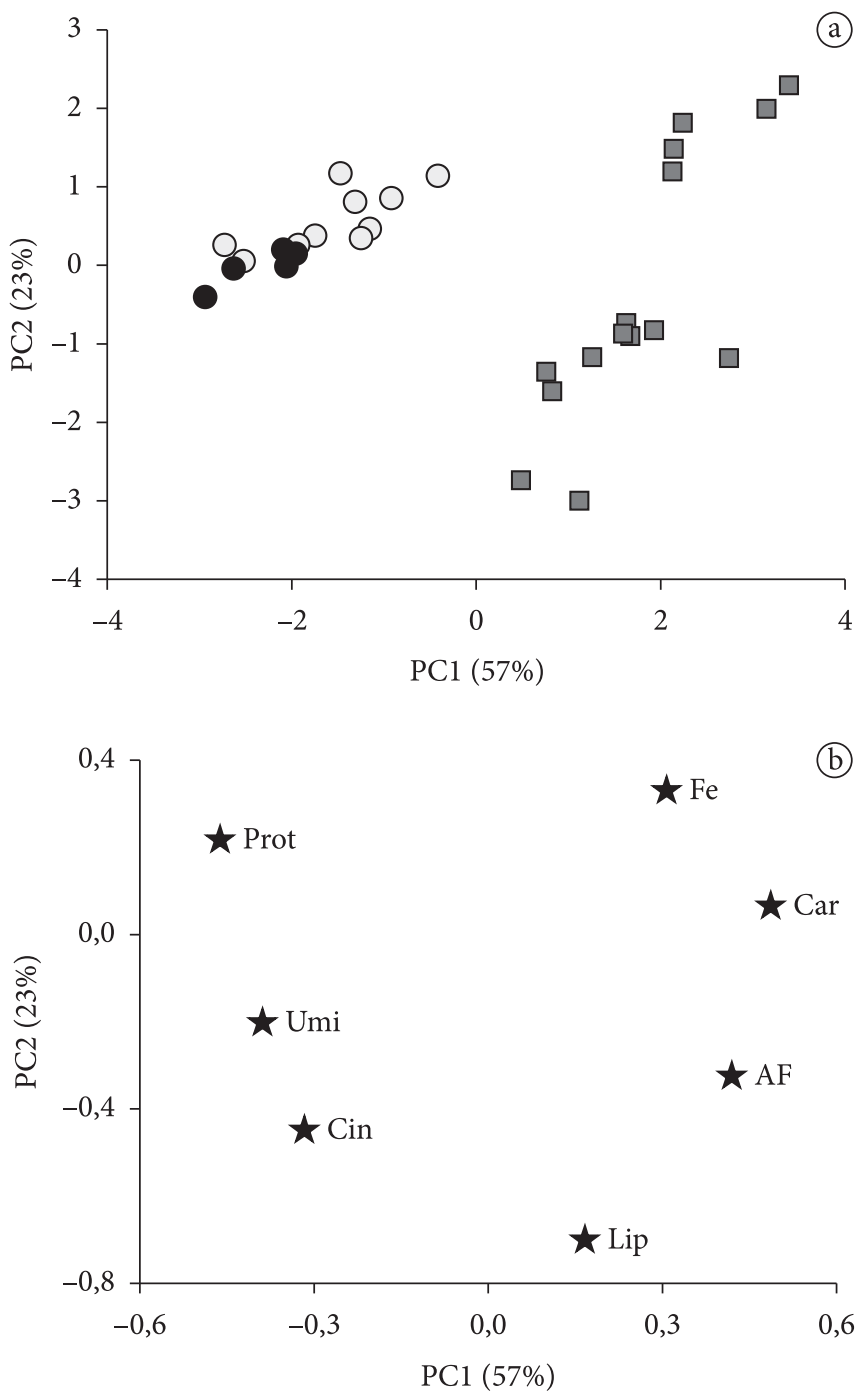

Figura 2. Gráficos de a) Scores e b) loadings. Círculos e quadrados representam farinhas de trigo e milho, respectivamente.

trigo apresentarem menor teor de ferro, continham maior porcentagem de cinzas, quando comparadas às farinhas de milho analisadas. Uma correlação inversa entre quantidade de cinzas e concentração de ferro pode ser um indicativo de problemas associados à qualidade nutricional dessas amostras.

Outra constatação importante está relacionada ao tipo de embalagem. Foi possível notar que farinhas acondicionadas em embalagens de plástico (círculos escuros) apresentaram menor quantidade de ácido fólico, quando comparadas às amostras armazenadas em embalagens de papel (círculos claros e quadrados). Essa constatação se deve, provavelmente, à incidência de luz durante o período de estocagem.

Este estudo pode fornecer ferramentas importantes para a avaliação dos programas de enriquecimento de alimentos com ácido fólico, principalmente, por apontar, preliminarmente, para a importância do tipo de embalagem para o acondicionamento das farinhas enriquecidas com a vitamina, além de indicar, de forma geral, qual tipo de farinha contém maior teor dos nutrientes adicionados e ainda se estabelecer correlação com outras variáveis estudadas. A observação simples dos valores, provavelmente não proporcionaria tal tratamento de dados.

Dados a respeito da concentração de ácido fólico e ferro em farinhas enriquecidas e comercializadas em alguns países já foram publicados. Rader, Weaver e Angyal (2000) obtiveram concentrações para a vitamina que variaram de 33 a $229 \mu \mathrm{g} .100 \mathrm{~g}^{-1} \mathrm{em}$ farinhas comercializadas nos Estados Unidos. Arcot, Shrestha e Gusanov (2002) constataram que o teor de ácido fólico oscilou entre 82 e $95 \mu \mathrm{g} .100 \mathrm{~g}^{-1}$, no mesmo tipo de matriz, disponível para consumo, também nos Estados Unidos, cuja regulamentação para o enriquecimento de farinhas com ácido fólico estipula $140 \mu \mathrm{g} .100 \mathrm{~g}^{-1}$. Gujska e Majewska (2005) relataram o valor médio de $237 \pm 7 \mu \mathrm{g} .100 \mathrm{~g}^{-1}$ para a concentração desse nutriente, em farinhas encontradas em mercados da Polônia (o enriquecimento não é obrigatório). Recentemente, Sadighi et al. (2008) avaliaram farinhas fortificadas com ferro no Irã e concluíram que $14 \%$ das amostras apresentaram quantidades aceitáveis do mineral, 74,4\% continham quantidade adequada e em $11,6 \%$ foi observado teor de ferro abaixo do esperado. As farinhas avaliadas no presente trabalho apresentaram variações apreciáveis nas concentrações de ferro e ácido fólico e esse comportamento pode ser explicado por dificuldades para efetuar os procedimentos de adição e homogeneização da vitamina e do mineral, além da relativa instabilidade do ácido fólico durante o período de estocagem, uma vez que as amostras avaliadas apresentavam prazo de validade diferenciado (essa variável não foi controlada) e ainda, problemas associados aos premix utilizados.

É importante destacar também, que as farinhas enriquecidas serão utilizadas como ingredientes para o preparo de diversos alimentos, incluindo pães, massas, bolos e biscoitos, entre outros. Durante o preparo desses alimentos para consumo, poderão ocorrer perdas da vitamina por degradação e lixiviação e solubilização de algumas formas de ferro, possíveis de se adicionar às farinhas, que irão interferir diretamente no conteúdo consumido de cada um dos nutrientes adicionados.

\section{Conclusões}

As amostras de farinhas avaliadas no trabalho apresentaram qualidade físico-química adequada às condições estipuladas pela Legislação Brasileira. Constatou-se também que o enriquecimento das farinhas está sendo realizado, entretanto, $\mathrm{o}$ teor de ácido fólico e ferro não está de acordo com o esperado, para a maioria dos produtos analisados. A aplicação da análise por componentes principais indicou uma diferenciação entre os componentes das farinhas de trigo e milho e a correlação entre as variáveis estudadas, além de apontar a importância do tipo de embalagem na concentração da vitamina.

\section{Referências bibliográficas}

AGÊNCIA NACIONAL DE VIGILÂNCIA SANITÁRIA - ANVISA. Legislação em Vigilância Sanitária. Disponível em: www.anvisa. gov.br/e-legis. Acesso em: 10 jan. 2008.

AGÊNCIA NACIONAL VIGILÂNCIA SANITÁRIA - ANVISA. Resolução - CNNPA nº 12, de 1978. Diário Oficial [da] República Federativa do Brasil, Brasília, DF, 24 jul. 1978. 
AGÊNCIA NACIONAL VIGILÂNCIA SANITÁRIA - ANVISA. Portaria no 354, de 18 de julho de 1996. Diário Oficial [da] República Federativa do Brasil, Brasília, DF, 22 jul. 1996.

AGÊNCIA NACIONAL VIGILÂNCIA SANITÁRIA - ANVISA. Resolução - RDC no 344, de 13 de dezembro de 2002. Diário Oficial [da] República Federativa do Brasil, Brasília, DF, 18 dez. 2002.

AGUIAR, M. J. B. et al. Defeitos de fechamento do tubo neural e fatores associados em recém-nascidos vivos e natimortos. Jornal de Pediatria, v. 79, n. 2, p. 129-134, 2003.

ANALYTICAL METHODS COMMITTEE. Recommendations for the definition, estimation and use of the detection limit. Analyst, v.112, p. 199-204, 1987.

ARCOT, J.; SHRESTHA, A. J.; GUSANOV, U. Enzyme protein binding assay for determining folic acid in fortified cereal foods and stability of folic acid under different extraction conditions. Food Control, v.13, p. 245-252, 2002.

ASSOCIATION OF OFFICIAL ANALYTICAL CHEMISTS - AOAC. Official methods of analysis. 18 $8^{\text {th }}$ ed. Maryland : AOAC, 2006.

BEEBE, K. R.; PELL, R. J.; SEASHOLTZ, M. B. Chemometrics: a practical guide. New York: John Wiley\&Sons, 1998.

BLIGH, E. G.; DYER, W. J. A rapid method of total lipid extraction and purification. Canadian Journal of Biochemistry and Physiology, v. 37, n. 8, p. 911-917, 1959.

BOEN, T. R. et al. Folic acid and iron evaluation in Brazilian enriched corn and wheat flours. Journal of the Brazilian Chemical Society, v. 19, n. 1, p. 53-59, 2008.

CZEIZEL, A. E.; DUDAS, I. Prevention of the first occurrence of neural tube defects by perioconceptional vitamin supplementation. The New England Journal of Medicine, v. 327, n. 226, p. 1832-1839, 1992.

FERREIRA, M. M. C. et al. Quimiometria I: calibração multivariada, um tutorial. Química Nova, v. 22, n. 5, p. 724-731, 1999.

GRILLO, E.; SILVA, R. J. M. Defeitos do tubo neural e hidrocefalia congênita. Por que conhecer suas prevalências? Jornal de Pediatria, v. 79, n. 2, p. 106-106, 2003.

GUJSKA, E.; MAJEWSKA, K. Effect of baking process on added folic acid and endogenous folates stability in wheat and rye breads. Plant Foods for Human Nutrition, v. 60, p. 37-42, 2005.
GUTKOSKI, L. C.; JACOBSEN, R. Procedimento para teste laboratorial de panificação - pão tipo forma. Ciência Rural, v. 32, n. 5, p. 873-879, 2002.

LYNCH, S. R. The impact of iron fortification on nutritional anaemia. Best Practice \& Research Clinical Haematology, v. 18, p. 333-346, 2005.

MOLLOY, A. M. The role of folic acid in the prevention of neural tube defects. Trends in Food Science \& Technology, v. 16, p. 241-245, 2005.

NEUHOUSER, M. L.; BERESFORD, S. A. A. Folic acid: are current fortification levels adequate? Nutrition, v. 17 , n. 10 , p. $868-872$, 2001.

RADER, J. I.; WEAVER, C. M.; ANGYAL, G. Total folate in enriched cereal-grain products in the United States following fortification. Food Chemistry, v. 70, p. 275-289, 2000.

RAO, B. S. N.; PRABHAVATHI, T. An in vitro method for predicting the bioavailability of iron from foods. American Journal of Clinical Nutrition, v. 31, p. 169-175, 1978.

RASPER, V. F. Quality evaluation of cereal and cereal products. In: LORENZ, K. J.; KULP, K. (Ed.). Handbook of cereal science and technology. New York: Marcel Dekker, 1991. p. 595-638.

REILLY, C. Too much of a good thing? The problem of trace element fortification of foods. Trends in Food Science \& Technology, v. 7, p. 139-142, 1996.

SADIGHI, J. et al. Flour fortification with iron: a mid-term evaluation. Public Health, v. 122, p. 313-321, 2008.

UNIVERSIDADE ESTADUAL DE CAMPINAS - UNICAMP. Tabela Brasileira de Composição de Alimentos - TACO. Campinas, 2006. Disponível em: <www.unicamp.br/nepa/taco>. Acesso em: 5 fev. 2008.

UNITED NATIONS SYSTEM STANDING COMMITTEE ON NUTRITION (ACC/SCN). United Nation Sub-Committee on Nutrition. Fourth Report on the World Nutrition Situation. Geneva, 2000.

WORLD HEALTH ORGANIZATION - WHO. The World Health Report 2002: Reducing Risks, Promoting Healthy Life. [S.l.], 2002. 